\title{
“O QUE DE FATO É SER UM PROFESSOR DE INGLÊS?” DESCOBRINDO A DOCÊNCIA NO CONTEXTO PIBID
}

\section{"WHAT IS ACTUALLY BEING AN ENGLISH TEACHER?” DISCOVERING TEACHING IN THE PIBID CONTEXT}

\author{
Rozana Aparecida Lopes Messias* \\ UNESP/FCL Assis

\section{Anna-Katharina Elstermann** UNESP/FCL Assis}

Resumo: O presente artigo retrata um estudo desenvolvido no âmbito da coordenação de um subprojeto PIBID/Letras-Inglês. O Programa Institucional de Bolsas de Iniciação à Docência (PIBID), instituído junto à CAPES, oportuniza que estudantes universitários de cursos de licenciatura vivenciem a realidade escolar, acompanhados por um professor da Educação Básica e orientados por um supervisor na universidade. No âmbito dessa ação, empreendemos uma investigação com vistas a retratar como os licenciandos participantes do projeto construíam suas visões sobre o papel dos professores de inglês nas escolas públicas brasileiras e de que maneira delinevam sua identidade docente. Amparadas nos pressupostos da pesquisa qualitativa, análise de conteúdo (KUCKARTZ, 2014; MAYRING, 2009), estudos sobre a constituição do PIBID como terceiro espaço (FELÍCIO, 2014) e a formação e profissionalização docente (TARDIF, 2013; SAVIANI, 2009) analisamos relatórios reflexivos e relatos dos participantes, gravados em reuniões de supervisão e posteriormente transcritos. Os resultados mostram que o cenário criado pela inserção dos graduandos na escola, além de aproximá-los da realidade da profissão, desmantela a hierarquia criada entre conteúdos de ensino e conteúdos teóricos.

Palavras-chave: Desenvolvimento de professores de inglês. PIBID. Papel do professor.

\begin{abstract}
This article presents a study developed within a PIBID/Languages (English) subproject. The Institutional Program of Scholarships for Teaching Initiatives (PIBID), created along with CAPES, allows university undergraduate students to experience public school reality, supported by a secondary school teacher and supervised by a university professor. In the scope of this project, we carried out an investigation to depict how students from a teacher training course who took part in the project have constructed their visions about the role of the English teacher in Brazilian public schools, as well as how they have built their teacher identity. Based on the assumptions of qualitative research, content analysis (KUCKARTZ, 2014; MAYRING, 2009), studies on the constitution of PIBID as
\end{abstract}

\author{
* Doutora em \\ Educação, rozana. \\ messias@unesp.br \\ ${ }^{* *}$ Doutora em \\ Linguística Aplicada, \\ elstermanna@unesp. \\ br
}


a third space (FELÍCIO, 2014) and training and education of teachers (TARDIF, 2013; SAVIANI, 2009) we studied reflective reports from participants, which were recorded at supervisory meetings and subsequently transcribed. The results show that the scenario created by the insertion of undergraduates in schools dismantles the hierarchy created between teaching practice and theoretical contents, in addition to bringing students closer to the reality of the profession.

Keywords: Development of English teachers. PIBID. Teachers’ roles.

\section{Introdução}

Durante o ano de 2016 e início de 2017 atuamos, conjuntamente, como coordenadoras do subprojeto PIBID (Programa Institucional de Bolsas de Iniciação à Docência), Letras/Inglês, núcleo da UNESP/Assis. Esse programa do governo federal propicia a inserção de jovens licenciandos na escola de Educação Básica, na sala de um professor que, também, recebe uma bolsa para acompanhar esse licenciando. O contexto criado pelo PIBID coloca em parceria três segmentos da carreira docente (professor formador, professor da educação básica e professor em formação inicial) em busca de um objetivo comum, qual seja, a melhoria da Educação Básica e a formação profissional docente (inicial e continuada).

Como coordenadoras do projeto, criamos um rol de atividades em que os três segmentos encontravam-se quinzenalmente e compartilhavam suas experiências, tanto a respeito dos materiais produzidos para as aulas e de suas respectivas aplicações, quanto a respeito de leituras acerca de textos teóricos que eram propostos como gatilho para reflexão conjunta e, também, para embasamento de ações pretendidas. Em um processo democrático, em que todos podiam expor suas dificuldades, insucessos e sucessos, as reuniões de supervisão (como chamávamos esses encontros) eram gravadas para que pudessem ser analisadas, posteriormente. Além das reuniões, todos produziam diários reflexivos que eram postados mensalmente em uma pasta do Google Drive, juntamente com todas as atividades pedagógicas produzidas no projeto (sequências didáticas, planos de aula, projetos pedagógicos etc). Para o desenvolvimento do presente artigo, nos pautaremos em transcrições de gravações de reuniões de supervisão e em relatórios reflexivos produzidos pelos estudantes (bolsistas de Iniciação à Docência).

Nesses materiais, buscaremos marcas de reflexões acerca dos papéis do professor, sobretudo dos bolsistas de Iniciação à Docência (ID), personagens que vivenciam suas primeiras experiências na sala de aula da escola pública, ora acompanhando a aula de um professor mais experiente, ora assumindo a regência de uma sala sob o olhar desse docente supervisor. Tendo como panorama tal cenário, desenvolvemos uma investigação de cunho qualitativo com o intuito de verificar nos relatos dos estagiários bolsistas os modos como esses constroem sua identidade docente. Para tal, consideramos que 
o PIBID pode ser entendido como um terceiro espaço, conceito cunhado por Bhabha (1999) e adaptado ao contexto do PIBID por Felício (2014). O terceiro espaço na vivência discente, nesse caso, é um entrelugar, no qual o estagiário bolsista deixa de ser aluno da graduação, mas ainda não pode ser considerado como um profissional professor. Em tal interstício, ele busca a configuração de sua identidade profissional docente. Nesse ínterim, tendo como parâmetro o momento da profissionalização docente (TARDIF, 2013), observamos, por meio de análise de conteúdo qualitativa (KUCKARTZ, 2014, MAYRING, 2009), como esses estudantes significam o ser professor e, mais ainda, ser professor de língua inglesa.

\section{Entre a escola e a universidade: formando professores em contexto PIBID}

O subprojeto PIBID-Letras/Inglês da UNESP-Assis é apresentado no documento formulado por uma das coordenadoras como um projeto que objetiva

colocar os bolsistas de iniciação à docência em Língua Inglesa e suas Literaturas em contato direto com o cotidiano da Escola de Educação Básica parceira, de modo que conheçam o Projeto Político Pedagógico dessa escola, participem de sua elaboração (quando for o caso), execução e avaliação. Todos os bolsistas participarão de reuniões de ATPC (Atividade de Trabalho Pedagógico Conjunto), do processo de preparação e de desenvolvimento das aulas em conjunto com os professores supervisores. Serão programadas atividades interdisciplinares em conformidade com os projetos da escola. (...) (Projeto PIBID - Letras/Inglês, FCL-Assis, 2014)

Além disso, o subprojeto é exposto como uma ação com vistas a “propiciar a reflexão em torno de temas de interesse geral, bem como contribuir para uma formação crítico-reflexiva tanto dos alunos da rede pública de ensino, quanto dos licenciandos e, também, dos professores atuantes em formação continuada”.

Motivadas por esses objetivos de organização e gestão, seguimos com uma investigação sobre a formação inicial de professores na conjuntura do PIBID. Na busca de estudos que tratassem do mesmo espaço educacional, deparamo-nos com a investigação de Felício (2014) que retrata o PIBID, desenvolvido em sua universidade (Unifau - MG), como um terceiro espaço. Esta é uma noção influenciada pelos estudos de Zeichner (2010) que, por sua vez, trata das relações entre universidade e escolas (como campo de atuação e formação) no desenvolvimento de futuros professores, nos Estados Unidos. A ideia de um terceiro espaço, apropriada por Zeichner e seguida por Felício, tem sua origem nos estudos de Homi Bhabha (1990), autor indo-americano, pesquisador dos estudos pós-coloniais e pós-estruturalistas. Em O Local da Cultura, Bhabha faz uma intrincada análise de textos literários e 
documentos do governo britânico, da época da Índia colonial. Nesse trabalho, o autor, na busca da definição das identidades, ultrapassa a ideia do lugar e reforça o pressuposto dos "lugares”. Para além dos lugares, no diálogo das diferenças, os “entre-lugares fornecem o terreno para a elaboração de estratégias de subjetivação - singular ou coletiva - que dão início a novos signos de identidade e postos inovadores de colaboração e contestação no ato de definir a própria ideia de sociedade” (BHABHA, 1990, p. 16).

A inserção de estudantes, em processo de formação inicial, no contexto escolar da Educação Básica permite que o graduando conviva com representantes de diversos segmentos desse espaço (professores, alunos, funcionários, pais de alunos, diretores, coordenadores, supervisores etc.). Nessa intrincada relação, diferenças afloram, acordos devem ser organizados e conflitos, muitas vezes, surgem e devem ser suplantados para que as relações cotidianas possam efetivar-se de maneira construtiva e harmoniosa. Pelo nosso entendimento da teoria de Bhabha, é no "encontro” que o terceiro espaço emerge e é nesse espaço que essa compreensão das diferenças e acordos é construída. O terceiro espaço representa uma intersecção que se cria na junção das diferenças que, apesar de carregar as características de cada lado, faz despontar as individualidades que não se afinam com nenhum dos lados originários. Na sua relação com a escola, o graduando encontra-se em uma situação intermediária, ele não é ainda um professor, mas também não é aluno da graduação. Exerce um papel que se situa no entremeio da atuação profissional. E nessa posição, busca construir a sua identidade docente.

\section{Dialogando e refletindo com/sobre a profissão}

'Considerar o PIBID como um terceiro espaço desmaterializa a ideia dicotômica que sustenta o binômio teoria x prática. De acordo com Zeichner, 2010, p. 487, “os terceiros espaços reúnem o conhecimento prático ao acadêmico de modos menos hierárquicos, tendo em vista a criação de novas oportunidades de aprendizagem para professores em formação”. Em termos de formação do professor, Saviani (2009) alude a diferentes paradigmas de formação docente, dentre os quais "o modelo dos conteúdos culturais cognitivos” que reforçam a valorização do domínio de conteúdos teóricos pelo futuro professor ou o "pedagógico-didático”, no qual são sublinhados os conteúdos didático-pedagógicos. O PIBID, então, configura o diálogo entre esses dois segmentos.

Ao historicizar as ações institucionais de formação de professores no Brasil, Saviani expõe que a legislação educacional brasileira, em vários momentos da história, buscou aproximar o modelo dos conteúdos culturais cognitivos do didático pedagógico. Todavia, chama a atenção para o fato de que "essa obrigatoriedade legal reveste-se, com frequência, de um formalismo que esvazia o sentido real desses componentes formativos” (SAVIANI, 2009, p. 151). De maneira resumida, realçamos o que aponta o autor sobre a única 
saída para sanar o dilema das instituições no que tange ao posicionamento frente à ação formativa, "considerando-se que o dilema resultou da dissociação de aspectos indissociáveis do ato docente, logicamente a saída do dilema implica a recuperação da referida indissociabilidade (SAVIANI, 2009, p. 151).

Por esse prisma, frisamos que em sua atuação nas escolas, os estudantes vivenciam ações de ensino-aprendizagem contextualizadas no que representa seu ambiente futuro de trabalho, a escola. Ensinar e aprender passam a ser preocupações de uma vivência que os desloca da posição cômoda de um estagiário que somente observa para a condição daquele que deve auxiliar o professor da sala, intervir e refletir sobre as ações dispensadas com os estudantes. Nesse entremeio, ele se vê obrigado a retomar o que aprendeu na universidade e transformar isso em conteúdo ensinável. Entendemos, assim como Zeichner (2010), que nessas ocasiões, teoria e prática imbricam-se de maneira significativa, desvelando conhecimentos que se materializam e se tornam significativos por se constituírem como produto da experiência vivenciada pelos envolvidos. Constroem-se, nesse ínterim, sentidos sobre o trabalho docente, a configuração da escola e a relação com os estudantes da educação básica.

Pensando nessa trajetória do processo de se formar professor no Brasil e em outros lugares do mundo, com relação à profissionalização docente, Tardif sublinha que "vista de uma perspectiva comparativista e internacional, a evolução recente do ensino não é de forma alguma linear, que ela é feita de continuidades, de desvios, de retrocessos e de avanços temporários.” (TARDIF, 2013, p. 553).

O autor expõe que a forma como o ensino evolui é desequilibrada e bastante diversa de acordo com os países e "mesmo segundo regiões de um mesmo país: ele não evolui no mesmo ritmo por toda parte e formas antigas convivem com formas contemporâneas”. (TARDIF, 2013, p. 553). As diferentes formas de conceber a profissão docente, de acordo com ele, passam pela idade da vocação, do ofício e da profissão.

O ensino na idade da vocação, tem início no século XVI, quando “o ensino está, então, principalmente entregue às comunidades religiosas protestantes e católicas” (TARDIF, 2013, p.554). Com seu fortalecimento no século XIX, pessoas leigas, na Europa e nos EUA, iniciam a ação de ensinar em “pequenas escolas elementares” (TARDIF, 2013, p. 554). Nessa época, o ensino era concebido como "profissão de fé”, no sentido de trabalhar e de expressar sua fé. Essa é uma fase de extrema precarização da profissão docente, professores não recebiam salários, ou mesmo recebiam quantidade irrisória. Para tornar-se professor,

Nesse contexto religioso, o ensino é considerado como uma vocação. O que é uma vocação? Essencialmente, trata-se de um movimento interior um elan íntimo, uma força subjetiva — pelo qual nos sentimos chamados a 
cumprir uma importante missão: ensinar, ou seja, professar sua fé religiosa junto às crianças. (TARDIF, 2013p. 555).

Em um processo de desconfessionalização e separação das estruturas religiosas, a educação no século XIX e XX começa a fazer parte, paulatinamente, das políticas governamentais. “A profissão de docente é gradualmente integrada a estruturas do Estado (nacional, federal, provincial, estatal, municipal, entre outras). Assim, a relação das professoras com o trabalho deixa gradualmente de ser vocacional, torna-se contratual e salarial” (p. 557). O autor expõe que a ampliação das escolas e a massiva presença das mulheres na carreira docente, embora ainda bastante vinculadas à ideia do ofício, exige que sejam criadas redes de formação de professores.

Entretanto, como em qualquer profissão, a experiência concreta do trabalho permanece o cerne do saber ensinar. Nas escolas normais, o aprendizado da profissão passa pela prática, pela imitação e pelo domínio das rotinas estabelecidas nas escolas pelas professoras experientes, bem como pelo respeito às regras escolares. (TARDIF, 2013, p.557)

Com o crescimento dos cursos universitários de formação profissional em geral e, também, dos cursos de formação de professores, a docência começa a configurar-se como uma carreira. Esse é um processo que atravessa o século XX, de acordo com o autor. De maneira mais específica, a sistematização da formação docente começa de forma mais contundente a partir da década de 80, nos EUA. As bases que sustentam a formação de professores devem pautar-se, então, nos conhecimentos produzidos por meio da investigação científica em uma perspectiva mais ampla, não desfocada da prática. Dessa forma, entendemos que “a profissionalização do ensino induz a uma visão reflexiva do ato de ensinar: o ensino não é mais uma atividade que se executa, mas uma prática na qual devemos pensar, que devemos problematizar, objetivar, criticar, melhorar” (TARDIF, 2013, p. 561).

De acordo com Tardif, em pleno século XXI, ainda convivem as três formas de pensar a profissão docente. O espaço entre as três "idades" da profissionalização docente se faz relevante em nossa reflexão sobre como os estudantes (bolsistas PIBID) constituem sua visão sobre o que é ser professor, pois essa é decisiva para a condução de suas atividades na escola. Por outro lado, para para os docentes formadores (supervisor e professor da Educação Básica) que acompanham o processo, compreender esse fenômeno pode auxiliar na condução das ações formativas.

\section{Metodologia e observações sobre os dados}

Para desenvolver o presente estudo, utilizamos a metodologia qualitativa de caráter hermenêutico-interpretativista, nos moldes explicitados por Lüdke e André (1986), quando afirmam que neste tipo de pesquisa há 
ênfase no processo, preocupação em se retratar a perspectiva dos participantes, além de o ambiente natural ser a fonte direta dos dados. O objetivo do estudo foi observado de forma holística e métodos indutivos foram usados para explorar os dados, ou seja, para obter hipóteses através dos dados empíricos. O trabalho com os dados foi realizado de modo exploratório e interpretativo seguindo a Análise Qualitativa de Conteúdo (MAYRING, 2009; KUCKARTZ, 2014). Nesse ínterim, fomos guiadas pelos seguintes questionamentos: (a) o que os graduandos pensam sobre o papel do professor de inglês e (b) de que maneira estão descobrindo esses papéis.

O contexto da pesquisa, conforme explicitado, foram as reuniões de supervisão do subprojeto PIBID Letras-Inglês da UNESP, câmpus de Assis. Nesses encontros, juntamente com os estudantes bolsistas e as professoras das escolas públicas, atuantes no projeto, refletíamos sobre as atividades dos graduandos, desenvolvidas nas salas de aula de inglês, nas escolas de Educação Básica (essas reuniões foram gravadas em áudio e depois transcritas). Para o presente estudo, utilizamos as transcrições de seis reuniões de supervisão e, ainda, relatórios reflexivos escritos pelos graduandos e entregues no final de cada mês. Todos os estudantes observados cursavam entre o segundo e o quarto ano de Letras, com habilitação em português e inglês. Todo o material selecionado foi examinado por meio da Análise Qualitativa de Conteúdo, uma variação da Análise Clássica de Conteúdo. Tal método é baseado em categorias para uma análise sistemática dos dados qualitativos (KUCKARTZ 2014, p. 6). Sendo assim, durante a leitura e categorização, elaboramos o seguinte esquema de categorias de análise.

\begin{tabular}{l|l|l|l|l}
\hline $\begin{array}{l}\text { CATEGORIA } \\
\text { PRINCIPAL }\end{array}$ & $\begin{array}{l}\text { SUB- } \\
\text { CATEGORIA }\end{array}$ & $\begin{array}{l}\text { EXCERTO } \\
\text { DE } \\
\text { DADOS }\end{array}$ & COMENTÁRIOS & $\begin{array}{l}\text { RESUMO } \\
\text { INTERPRETATIVO }\end{array}$ \\
\hline $\begin{array}{l}\text { nome da } \\
\text { categoria } \\
\text { principal }\end{array}$ & $\begin{array}{l}\text { nome da sub- } \\
\text { categoria se } \\
\text { houver }\end{array}$ & $\begin{array}{l}\text { Excerto } \\
\text { dos dados } \\
\text { relacionado } \\
\text { a categoria }\end{array}$ & $\begin{array}{l}\text { Comentários das } \\
\text { pesquisadoras }\end{array}$ & \\
\hline
\end{tabular}

Abaixo elencamos as categorias desenvolvidas no estudo:

\begin{tabular}{l|l}
\hline CATEGORIA PRINCIPAL & SUB-CATEGORIA \\
\hline \multirow{2}{*}{ Características do professor } & $\begin{array}{l}\text { Conhecimentos prévios } \\
\text { Experiência pessoal } \\
\text { Características do professor } \\
\text { Personalidade do professor }\end{array}$ \\
\hline Relação professor-aluno & $\begin{array}{l}\text { Relação positiva } \\
\text { Desafios na relação }\end{array}$ \\
\hline Entrosamento de teoria e prática & \\
\hline
\end{tabular}


Conclusão

\begin{tabular}{l|l}
\hline CATEGORIA PRINCIPAL & SUB-CATEGORIA \\
\hline Descoberta do papel do professor & $\begin{array}{l}\text { Planejado vs. real } \\
\text { Conteúdos } \\
\text { Preparação de aula } \\
\text { Técnicas/ Métodos }\end{array}$ \\
\hline Realidade na sala de aula & \\
\hline Visão de ensino-aprendizagem & \\
\hline Ensino-aprendizagem de inglês & \\
\hline
\end{tabular}

Conforme o quadro anterior, as categorias que sobressaíram nos diários reflexivos e transcrições das reuniões de supervisão observadas foram: Características do professor, Relação professor-aluno e Realidade na sala de aula; todas elas, por sua vez, apresentaram várias subcategorias. Na categoria Características do professor, juntamos trechos que manifestam a importância de conhecimentos de várias áreas que são úteis para a atuação como professor de inglês; as experiências pessoais que influenciam a vida profissional do professor e características de personalidade que podem favorecer, ou não, a relação do professor com sua respectiva turma. A categoria Relação professor-aluno trata, como o nome da categoria já revela, da relação entre professor e aluno da perspectiva dos bolsistas de Iniciação à Docência, testemunhada em suas primeiras experiências na sala de aula. A ênfase incide nas dificuldades em construir uma boa relação com os alunos, os sucessos nos pequenos desafios com alunos, vivenciados individualmente, entre outros. Já a categoria Realidade na sala de aula trata de temas como desafios na preparação de aula, o uso de técnicas e métodos no ensino de inglês, e também sobre como o conteúdo previsto para as aulas pode ser ministrado a partir de acontecimentos reais do dia-a-dia, em uma escola pública.

As outras categorias contêm uma quantidade menor de trechos, no entanto, não são menos importantes. Na categoria Entrosamento de teoria e prática, encontramos trechos de falas dos licenciandos sobre como foi importante poder testar teorias aprendidas nas disciplinas do curso de Letras e refletir sobre elas à luz da realidade da escola pública brasileira. Alguns excertos dos dados retratam, explicitamente, a descoberta do papel do professor de inglês, durante a atuação no projeto em geral ou durante uma aula específica, como observamos na categoria Descoberta do papel do professor. Finalmente, as últimas duas categorias são Visão de ensino e aprendizagem e Ensino e aprendizagem de inglês e demonstram o que os licenciandos pensavam sobre teorias e abordagens de ensino e aprendizagem de línguas estrangeiras em geral, especificamente para a área de inglês como língua estrangeira. 
A seguir, examinaremos alguns trechos escolhidos com a finalidade de discutir seu conteúdo em relação às perguntas de pesquisa deste estudo. Devido às limitações do presente trabalho, selecionamos as categorias que nos pareceram mais recorrentes.

\section{Teoria e prática no projeto PIBID e no dia-a-dia da escola pública}

Os três excertos de diários reflexivos, a seguir, nos mostram como, pela compreensão dos licenciandos participantes do projeto, o PIBID constitui um terceiro espaço (FELICIO, 2014; ZEICHNER, 2010), onde são reunidos conhecimentos práticos aos conhecimentos acadêmicos. Da mesma forma, fica explícito como consideram essa junção de teoria e prática importante para sua formação.

Na universidade, aprendo as teorias, a gramática, os métodos de ensino, porém, eu sou a aluna, neste caso. Quando vou à escola realizar meu estágio, estou no papel de (quase) professor. Fico ali absorvendo tudo que a professora passa aos seus alunos, vendo de perto como tudo aquilo que estudo na universidade se aplica a uma sala de aula e tenho ainda a liberdade de desenvolver atividades junto aos meus colegas estagiários e aplicá-las aos alunos. (Da, rel. 01, ênfase nossa ${ }^{1}$ )

Nesse primeiro trecho observamos que, além da percepção sobre o entrosamento de teoria e prática no projeto, ao observar esse fenômeno na atuação da professora supervisora, o licenciando reconhece que também ele, como aluno de graduação e “quase-professor”, percebe a possibilidade (e "liberdade”, Da. rel. 01) de planejar e realizar atividades na sala de aula. Ou seja, depreende a possibilidade de, ele mesmo, agregar teorias aprendidas no curso de Letras com a prática vivida na escola pública.

Outro fator de suma importância no programa é a união de teoria e prática. Com este contato, temos a visão ampla de teoria e prática devem sempre estar juntas e que o professor deve ser também um pesquisador. (L., rel. 06, ênfase nossa)

Nesse segundo trecho, o aluno L. menciona o fato de que o professor deve ser, também, um pesquisador. Isso nos remete à função dos licenciandos no projeto PIBID que, além de participarem ativamente das aulas de inglês nas escolas públicas parceiras, também recebiam tarefas de estudo voltadas para a reflexão e discussão de textos teóricos nas reuniões de supervisão do próprio projeto. $\mathrm{O}$ feito de associar as noções desses materiais, tratados nas reuniões, ou em disciplinas da graduação, com as experiências da escola, faz com que os alunos compreendam o que pode configurar-se como uma pesquisa-ação na prática docente, mesmo que em formato reduzido. $\mathrm{O}$ ato de

\author{
${ }^{1}$ A nomenclatura \\ para a sistematização \\ dos dados segue \\ da maneira \\ seguinte: Nome \\ do/da participante \\ abreviado, número \\ do relatório reflexivo \\ desse/a participante \\ ou trecho de \\ transcrição.
}


observar, desde o início, o diálogo entre as teorias na prática faz-nos esperar que esses alunos, futuros professores, levem consigo essa experiência para suas futuras atividades como professores de língua. Essa é uma ação de formação inicial que, pelo que observamos, pode resultar em profissionais que alcancem uma atuação mais reflexiva e renovadora.

Os estagiários do Pibid possuem a oportunidade de aplicar a teoria ensinada na graduação, em que os estágios obrigatórios do último ano não nos tornam capazes de enfrentar uma sala de aula quando estivermos formados. (N., rel. 19, ênfase nossa)

Nesse terceiro trecho, o aluno N. acrescenta a afirmação da importância da junção explícita entre teoria e prática no projeto. Para ele somente o estágio obrigatório ${ }^{2}$ da licenciatura em Letras não seria suficiente para prepará-los para a carreira como professores de língua. Temos ressaltada a questão de como a atuação no PIBID faz uma grande diferença na formação inicial desses graduandos.

Frisamos nessas observações que, para nós, a questão de separar teoria e prática está superada para os estudos da educação e do ensino, de maneira geral. Todavia, o fato de os próprios estudantes perceberem, em sua vivência, que essa separação é uma falsa dicotomia, desvela um contexto em que a natureza do conhecimento perde a hierarquização (SAVIANI, 2009), muitas vezes, velada na universidade. Essa visão, construída pelos próprios estudantes, tem potencial para desmaterializar a divisão entre o que é científico e prático.

Por esse ângulo, retomamos Saviani em sua proposição da análise de livros didáticos como uma atividade esclarecedora da relação entre o modelo de formação voltado para “os conteúdos culturais cognitivos” e o “pedagógico-didático”. Para o autor, se conseguirmos “evidenciar a ligação entre os dois aspectos que caracterizam o ato docente, ou seja, evidenciando os processos didático-pedagógicos pelos quais os conteúdos se tornam assimiláveis pelos alunos no trabalho de ensino-aprendizagem, o dilema será superado (SAVIANI, 2009, p. 152).

\section{Descobrindo-se docente}

Montamos uma atividade com esta música e levamos para os alunos. E a professora deixou que nós aplicássemos a atividade. Foi muito bacana! Senti-me professora! (Da., rel 01, ênfase nossa)

O PIBID me ajudou a me descobrir como docente e proporcionou toda uma orientação, essencial para todo processo de iniciação à docência. (K., rel.02, ênfase nossa)

\footnotetext{
2 Na época, entre 2014 e 2016, a maioria dos alunos da UNESP- FCL/Assis, do curso de Letras, ainda estudavam em uma grade que previa somente dois semestres de estágio obrigatório, no último ano do curso.
} 
Os excertos anteriores ilustram como a prática na sala de aula, vivenciada pelos estudantes que, pela primeira vez, atuam como professores pode auxiliá-los na sua descoberta profissional. Isso mostra como a prática é essencial para a construção do papel individual de professor; somente ler e estudar sobre as teorias de ensino não faz com que alguém se torne um profissional de ensino. O PIBID oportunizou para esses bolsistas esse espaço de descoberta, muito mais do que o estágio que, na época, compunha apenas os dois semestres finais do curso. O excerto a seguir reforça tal ideia, a reflexão do aluno nos mostra como a identidade docente não se constrói de um dia para o outro, mas que é um processo que acontece ao longo de várias experiências pedagógicas.

Em uma turma com alunos de faixa etária diferentes e tão próxima da minha, ainda não sabia mostrar o meu papel, o que eu representava. Eu ainda não havia construído a minha identidade como professora. (N., rel. 03, ênfase nossa)

O Pibid é esse projeto que nos dá todo o auxílio para que possamos aprender como é ser de fato um professor, como se portar dentro de uma sala de aula, como organizar uma aula, como dar uma aula atrativa para os alunos, como conhecer os alunos um por um e o ritmo da sala, (J., rel. 09, ênfase nossa)

Nenhuma sala de aula é igual, nenhum aluno é igual ao outro, mas o propósito de um professor é sempre o mesmo: ensinar e, através do Pibid conseguimos compreender o que de fato é ser um professor, o quão desgastante é, quando um aluno te diz que mesmo se tivesse uma faculdade de graça para ele fazer, nunca faria um curso para ser professor. (J., rel. 09, ênfase nossa)

Nesse caminho, em busca da constituição de sua identidade docente, conforme observamos nos excertos anteriores, os estudantes vivenciam experiências na sala de aula da Educação Básica que os auxiliam a compreender as demandas por que passam esses profissionais. Preocupações tais como o comportamento que o docente deve demonstrar em sala de aula, a organização do trabalho pedagógico de maneira ampla (preparar a aula, ministrar a aula, atrair a atenção dos alunos e mantê-los interessados) materializam-se nos momentos em que o bolsista PIBID compartilha a sala de aula com seu professor supervisor. Todas essas questões deflagradas trazem consigo, também, “as agruras” do ser docente no século XXI. O desprestígio da profissão aflora na fala dos adolescentes que interpelam os bolsistas com comentários pejorativos referentes à profissão.

Esse quadro nos fez reportar, mais uma vez, as ideias de Tardif (2013), que, ao retratar o processo de profissionalização docente no mundo e no Brasil, relata que convivemos, ainda, com características das diferentes fases do processo histórico de constituição da carreira docente (vocação, ofício e trabalho). Pensamos que essa perspectiva torna a profissão docente pouco 
atrativa pois, embora estejamos numa era em que leis e regras regem o labor docente, a desvalorização dos salários e das condições de trabalho desse profissional o aproxima do professor do século XIX. Esse quadro remete à era do ofício, início da organização efetiva das escolas, quando professores leigos que atuavam, em sua maioria mulheres, eram mal remunerados e trabalhavam em condições precárias.

Depois que você entra em uma escola pública não da (sic) pra ter aquele sonho utópico de que você vai entrar na cabeça das crianças e mudar a vida dela (sic). Aliás, primeiro temos que quebrar o estereótipo de que professor é vocação. Não é, é uma profissão como outra qualquer em que você estuda e é habilitado para exercê-la. (Is, rel. 14, ênfase nossa)

O relato anterior demonstra que o espaço criado pela práxis pedagógica mobiliza nos alunos reflexões determinantes na constituição de sua identidade profissional. Nesse caso, o estudante refuta a ideia de que a carreira docente seja mobilizada por um sentimento de vocação, muito comum e até mesmo reforçado quando se publicizam, para os jovens, as diferentes carreiras disponíveis no vestibular, por exemplo. A idade da vocação entre outras características, de acordo com Tardif, caracterizava-se pela baixa autonomia das professoras que estavam sujeitas a várias formas de controle externas, pelos religiosos, pelos homens, pelos pais, por seus superiores, pelos que as pagavam, entre outros (TARDIF, 2013, p. 556). O discurso desgastado de que para ser professor é preciso ter vocação é desmateriazado quando se abre espaço para que as demandas da prática sejam cotejadas com os saberes produzidos no âmbito acadêmico.

\section{A importância dos conhecimentos específicos para ser professor de inglês}

Fazer parte do projeto Pibid me fez crescer como profissional, me capacitar antes de trabalhar um determinado conteúdo com os alunos, buscar diminuir minhas falhas e estar segura ao ensinar, como graduanda, aprendi a absorver melhor os conteúdos principalmente nas aulas de inglês e assim me enxergar como futura professora que terá o dever de dominar o conteúdo para ensiná-lo aos alunos, e buscar sempre renovar minhas técnicas e material didático para as aulas. (N., rel. 19, ênfase nossa)

Enquanto aluna, pude perceber o quanto meu inglês melhorou no sentido gramatical, pois estando em sala de aula temos que estar sempre atentos a gramática para poder explicar aos alunos e também minha expressão melhorou, pois estamos sempre usando a língua inglesa para tentar explicar, mesmo que alternando com inglês/português para que os alunos entendam melhor. (K., rel. 12, ênfase nossa)

O impacto do projeto também foi muito gratificante para mim, como bolsista, porque eu também tinha medo e insegurança para falar em 
inglês, mas no final pude perceber que não tinha mais (Aluna R., rel. 10, ênfase nossa)

Ainda pensando na questão da profissionalização, a área específica do ensino de línguas estrangeiras possui uma particularidade que a torna muito complexa e a diferencia do ensino de língua portuguesa, por exemplo. Pela nossa vivência como professoras de língua e metodologia de ensino de línguas, observamos que o evento de lidar com uma língua-cultura diversa da nossa instiga nos licenciandos em língua estrangeira preocupações contundentes quanto a sua proficiência linguística em sala de aula, como profissional. Essa insegurança faz com que, em um curso de habilitação dupla português e língua estrangeira, muitos optem por não trabalhar com língua estrangeira. Mais uma vez, verificamos que a aproximação entre o universo acadêmico e a escola cria e recria condições para que tanto as inseguranças quanto a proficiência na língua alvo sejam paulatinamente sanadas ou, pelo menos, minimizadas, tanto nas ações na escola, quanto nas atividades da academia.

\section{Algumas considerações}

Procuramos ao longo do estudo apresentado, desvelar as formas como um trabalho efetivamente conjunto entre escola e universidade pode ser exitoso na formação de professores. No caso do PIBID, constatamos assim como Felício (2014) que o PIBID configura uma experiência que mobiliza um terceiro espaço (BHABHA, 1990), entremeio onde o estudante em formação assume um terceiro papel, deslocado do ser docente (que ainda oficialmente não é) e de aluno de graduação (já que na escola de Educação Básica ele não é aluno).

Após estudar os dados coletados por meio das transcrições das gravações das reuniões conjuntas e dos relatórios reflexivos, produzidos individualmente pelos bolsistas PIBID, verificamos que ademais de entrar em contato com questões referentes à própria profissão docente, o estudante também constrói sua própria identidade profissional. Arriscamos afirmar que essas relações que se efetivam na escola (aluno x professor, professor $\mathrm{x}$ teoria, professor $\mathrm{x}$ prática, teoria $\mathrm{x}$ prática) desconstroem os binarismos criados por uma sociedade que desprestigia os saberes da prática e da experiência, ignorando a sua indissociabilidade do saber teórico. Esse é um espaço autêntico em que pensar a "profissionalidade docente" constitui-se como uma experiência que interfere na formação de futuros professores, tanto quando o auxilia a superar suas dificuldades com relação ao conteúdo, à metodologia, à dinâmica da sala de aula etc, quanto ao abrir espaço para que possa refletir sobre quem é e o que faz esse profissional que ele "pretende ser".

Finalmente, após explanar sobre alguns aspectos dos temas que selecionamos para analisar nos dados que coletamos durante o acompanhamento 
das atividades desenvolvidas no subprojeto Letras-Inglês da UNESP/Assis, estamos certas de que muitas outras ideias poderiam ter sido exploradas e de que este é um estudo que deve ser aprofundado. Esperamos que o compartilhar dessa vivência particular, nossa, possa servir de parâmetro para que estudantes em formação possam relacionar suas experiências. Da mesma forma, mesmo cientes de quão preambular é nosso estudo, esperamos mostrar que não há mais lugar nos cursos de licenciatura para uma visão elitista e dicotômica do conhecimento, uma vez que saber e fazer são igualmente importantes no trabalho de um profissional professor.

\section{Referências}

BHABHA, Homi K. O local da cultura. Belo Horizonte: Ed. UFMG, 1990.

FELÍCIO, H. M. S. O PIBID como "terceiro espaço” de formação inicial de professores. Revista Diálogo Educacional, Curitiba, v. 14, n. 42, p. 415-434, 2014.

KUCKARTZ, U. Qualitative Inhaltsanalyse. Methoden, Praxis, Computerunterstützung. Weinheim \& Basel: Beltz Juventa. 2nd edition, 2014.

MAYRING, P. Qualitative Inhaltsanalyse. In: FLICK, U.; von KARDORFF, E.; STEINKE, I. (Eds): Qualitative Forschung. Ein Handbuch. Reinbek: Rowohlt Taschenbuch. 7th edition. p. 468-475, 2009.

SAVIANI, D. Formação de professores: aspectos históricos e teóricos do problema no contexto brasileiro. Revista Brasileira de Educação. v. 14 n. 40, jan./abr. 2009.

TARDIF, M. A profissionalização do ensino passados trinta anos: dois passos para a frente, três para trás. Educação e Sociedade, Campinas, v. 34, n. 123, p. 551-571, abr-jun. 2013.

ZEICHNER, K. Repensando as conexões entre a formação na universidade e as experiências de campo na formação de professores em faculdades e universidades. Educação. Santa Maria, v. 35, n.3, p. 479-504, set./dez. 2010.

Recebido em outubro/2018.

Aceito em dezembro/2018. 